\title{
Challenges in the Management of a Patient with Myxoedema Coma in Ghana: A Case Report
}

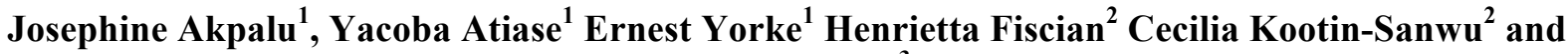 \\ Albert Akpalu ${ }^{3}$
}

Ghana Med J 2017; 51(1): 39-42～DOI: http://dx.doi.org/10.4314/gmj.v51i1.8

\begin{abstract}
${ }^{1}$ Endocrinology Unit, Department of Medicine and Therapeutics, School of Medicine and Dentistry, College of Health Sciences, University of Ghana, P.O. Box GP 4236, Accra, Ghana, ${ }^{2}$ Endocrinology Unit, Korle Bu Teaching Hospital, P.O .Box KB 77,Korle Bu, ${ }^{3}$ Neurology Unit, Department of Medicine and Therapeutics, School of Medicine and Dentistry, University of Ghana, PO Box GP 4236, Accra, Ghana
\end{abstract}

Corresponding author: Dr. Josephine Akpalu

E-mail: janduah@yahoo.com

Conflict of interest: None declared

\section{SUMMARY}

Myxoedema coma is a rare life-threatening disease, and it is essential that it is managed appropriately to reduce the associated high mortality. However, in the setting where efficient healthcare delivery is hampered by inadequacies, the management of such cases may pose a significant challenge. We present the case of a middle-aged woman diagnosed with myxoedema coma and severe hyponatremia. The case report highlights some of the challenges that may be encountered during the management of myxoedema coma in similar settings and outlines the management strategies undertaken to overcome them in the absence of national guidelines. It also brings to the fore the need for clinicians to look out for clinical features suggestive of hypothyroidism particularly among high risk individuals for early diagnosis and treatment.

Funding: None declared

Keywords: myxoedema coma, management, challenges, Ghana

\section{INTRODUCTION}

Myxoedema coma (MC) is an uncommon but severe, life-threatening form of decompensated hypothyroidism. ${ }^{1}$ The incidence in western countries is reported to be 0.22 million per year, however, there is a paucity of data from countries adjacent to the equator. ${ }^{2}$ Myxoedema coma is a medical emergency associated with high mortality rates ranging from $25-60 \%$ even with the best possible treatment and settings. ${ }^{1,3}$ Patients need to be treated in an intensive care unit with strict compliance to recommended management principles as much as possible. $^{4}$

However in healthcare facilities inundated by inadequacies, some of these commonly recommended treatment modalities may either not be available or not easily accessible. These insufficiencies include the unavailability of the required facilities for the diagnosis, treatment and monitoring of critically-ill patients. This can make the proper management of patients with $\mathrm{MC}$ a formidable task. We present a report of a patient managed for $\mathrm{MC}$ with severe hyponatraemia to highlight some difficulties that may be encountered in the management of such patients in similar settings in Ghana.

\section{CASE REPORT}

A 53-year-old female, was admitted at a secondary care facility with a two-day history of vomiting and extreme weakness with inability to walk or sit. She was noted to have recurrent episodes of both alteration of consciousness and hypotension with impalpable peripheral pulses. She was managed as a case of cardiogenic shock due to myocardial infarction or possible pulmonary embolism. Echocardiography performed outside the hospital revealed mild pericardial effusion, prompting the suspicion of hypothyroidism. A thyroid function test confirmed the diagnosis of primary hypothyroidism and she was subsequently referred to the endocrinology unit of a teaching hospital. She was brought in by her daughter who confirmed that the patient had been experiencing generalized weakness for the past 3years which became severe prior to presentation.

In addition, she had complained of fatigue, lethargy, constipation, swelling of the feet, hair loss and had developed a slow speech with hoarseness of voice. There was no history of cold intolerance or an anterior neck swelling. 


\section{Case Report}

She had hypertension and was on Amlodipine 10mg once daily. There was no past history of thyroidectomy, no previous exposure to radiation and no personal or family history of thyroid disease.

On physical examination she had facial puffiness, nonpitting oedema of hands and feet, dry coarse skin and alopecia. There was pallor of her mucous membranes, she was anicteric with a temperature of $36.7^{\circ} \mathrm{C}$. She had a pulse rate of $48 \mathrm{beats}$ per minute, regular but of small volume with blood pressure of $70 / 50 \mathrm{mmHg}$. Jugular venous pressure was not raised, her apex was not visible or palpable. The first and second heart sounds were heard but soft in nature. Her respiratory effort was poor with oxygen saturation of $81 \%$ on room air, arterial blood gases however could not be done. The Glasgow coma scale (GCS) was 4/15. She had hypotonia and power of zero in all her limbs.

Biochemical results from the referring hospital showed a TSH of $90.6 \mathrm{uIU} / \mathrm{L}(0.34-5.6)$, sodium of $92 \mathrm{mmol} / \mathrm{L}$ (135-150) and potassium of 2.3mmol/L (3.5-5.0) (Table 1). A diagnosis of $\mathrm{MC}$ with severe hyponatraemia and hypokalaemia in a patient with primary hypothyroidism was made and the possibility of a pericardial tamponade was investigated. Laboratory and radiological investigations were also performed to identify the possible precipitating condition which in this instance was myocardial infarction, stroke or infection.

A repeat $\mathrm{TSH}$, sodium and potassium on presentation were $138 \mathrm{uIU} / \mathrm{L}, 98 \mathrm{mmol} / \mathrm{L}$ and $3.4 \mathrm{mmol} / \mathrm{L}$ respectively (Table 1). Troponin I and T were $0.16 \mathrm{ng} / \mathrm{ml}(0.00-0.16)$ and $0.017 \mathrm{ng} / \mathrm{ml}(0.000-0.014)$ respectively. Electrocardiography done showed sinus bradycardia with small voltages and chest X-ray revealed cardiomegaly. A second echocardiography showed hypertensive heart disease and mild pericardial effusion with no evidence of pericardial tamponade.

Computed Tomographic Scan of brain was normal. Urine culture yielded E coli sp. Other results included random serum cortisol of $1029 \mathrm{nmol} / \mathrm{L}$ [171 - 536], haemoglobin $6.5 \mathrm{~g} / \mathrm{dl}$ with normocytic, normochromic cells, white blood cells count of $11.9 \times 10^{9} / \mathrm{L}$ with neutrophilia. Serum total and LDL cholesterol of $4.24 \mathrm{mmol} / 1$ and $3.29 \mathrm{mmol} / \mathrm{L}$ respectively were recorded. Ultrasonography of the thyroid gland revealed a heterogeneous gland, which was otherwise normal. Thyroid antibodies namely thyroglobulin and thyroid peroxidase antibodies were not elevated.

The patient had to be managed on the medical ward since no bed was available in the intensive care unit of the hospital. Oxygen was given by face mask and her oxygen saturation later increased to $99 \%$. Due to the possibility of an underlying myocardial infarction (ECG had not been done yet) and the lack of cardiac monitoring, she was cautiously started on Levothyroxine 100 micrograms via nasogastric $(\mathrm{NG})$ tube.

Oral Levothyroxine was given instead of the recommended IV Levothyroxine (T4) or Tri-iodothyronine (T3) because these parenteral preparations were not available in Ghana at the time. The dose of levothyroxine was subsequently increased to 125 micrograms after ECG, troponins and echocardiography results made the diagnosis of myocardial infarction unlikely. The hyponatremia was corrected by giving IV hypertonic saline in addition to fluid restriction and the avoidance of hypotonic IV fluids. The sodium requirement was estimated based on the formula:

Sodium requirement $=$ total body water $\mathrm{x}$ (desired sodium concentration - current sodium concentration). We aimed at increasing sodium levels by a maximum of $8 \mathrm{mmol} / \mathrm{L}$ within 24 hours. The estimated sodium requirement of $240 \mathrm{mmol}$ in 24 hours was administered by adding approximately $22 \mathrm{mls}$ of $23 \%$ hypertonic saline to a litre of $0.9 \%$ saline. A repeat sodium level was only possible on the third day of admission in our circumstances (Table 1). The hypertonic saline was given as and when available until her serum sodium was $129 \mathrm{mmol} / \mathrm{L}$ in the second week of admission.

Hypokalaemia was initially corrected by giving IV potassium chloride $20 \mathrm{mmol}$ in $500 \mathrm{ml}$ of normal saline and subsequently maintained on oral potassium chloride $1200 \mathrm{mg}$ three times daily. Intravenous hydrocortisone $100 \mathrm{mg}$ 8hourly was started after random serum cortisol sample was taken. This was however stopped upon the receipt of the cortisol result which was suggestive of an appropriate adrenocortical response to stress. She developed recurrent episodes of hypoglycaemia and had to be fed frequent small meals to correct and prevent these episodes. The urinary tract infection was treated with IV Ceftriaxone $2 \mathrm{~g}$ once daily.

By the second day the patient was conscious but drowsy, blood pressure and pulse rate had increased averaging about $100 / 60 \mathrm{mmHg}$ and 80 beats per minute respectively. She was fully conscious and alert on the third day with an increase in power in all the limbs to grade 3 by the ninth day. Her temperature initially increased from $36.7^{\circ} \mathrm{C}$ to $38.1^{\circ} \mathrm{C}$ by the fourth day but later subsided with the antibiotic therapy.

On the tenth day of admission her antihypertensive medication had to be introduced and she was subsequently discharged home on oral levothyroxine 125 micrograms once daily. After a month of thyroxine therapy, the facial and bodily swelling had completely resolved with normal TSH after 2 months (Table 1). 


\section{Case Report}

\begin{tabular}{llllll}
\hline \multicolumn{6}{l}{ Table 1 Electrolyte and thyroid functions test } \\
\hline & $\begin{array}{l}\text { Sodium } \\
(\mathbf{m m o l} / \mathbf{L})\end{array}$ & $\begin{array}{l}\text { Potassi- } \\
\mathbf{u m} \\
(\mathbf{m m o l} / \mathbf{L})\end{array}$ & $\begin{array}{l}\text { Chloride } \\
(\mathbf{m m o l} / \mathbf{L})\end{array}$ & $\begin{array}{l}\text { TSH } \\
(\mathbf{u I U} / \mathbf{L}\end{array}$ & $\begin{array}{l}\text { FT } 4 \\
(\mathbf{p m}\end{array}$ \\
\hline $\begin{array}{l}\text { Preadmis- } \\
\text { sion }\end{array}$ & 92 & 2.3 & 61 & 90.6 & $<5$ \\
$\begin{array}{l}\text { Presentation } \\
\text { Day } 3\end{array}$ & 98 & 3.4 & 58 & 138 & $<5$ \\
\hline 2months & 111 & 3.4 & 73 & - & - \\
$\begin{array}{l}\text { 4months } \\
\text { Normal } \\
\text { range }\end{array}$ & 134 & 4.5 & - & 0.9 & - \\
\hline
\end{tabular}

\section{DISCUSSION}

Myxoedema coma (MC) is a rare, life threatening medical emergency. ${ }^{1}$ About $95 \%$ of all cases of MC coma is due to primary hypothyroidism (primary disorder of thyroid gland) with central hypothyroidism (disorder of the pituitary or hypothalamus) constituting about $5 \%$. Myxoedema coma is more common in elderly females often with longstanding, undiagnosed hypothyroidism with infection being the leading precipitating factor ${ }^{3,5}$ as demonstrated by our patient.

Cerebrovascular accidents, congestive cardiac failure, gastrointestinal bleeding, and various sedative drugs may also precipitate MC. ${ }^{6}$ Another common precipitating factor is the discontinuation of thyroxine replacement in critically ill patients. ${ }^{4}$ However for some patients, hypothyroidism is first diagnosed at the time of $\mathrm{MC}$ as shown in this report. ${ }^{7}$

\section{Diagnostic challenges}

Our patient had clinical features suggestive of hypothyroidism long before her presentation. However, delay in seeking medical attention could have contributed to the late diagnosis of hypothyroidism. In addition, clinical features of hypothyroidism may be non-specific and without a high index of suspicion diagnosis is often delayed. ${ }^{4}$ This case highlights the importance of screening for hypothyroidism in patients with suggestive clinical features, particularly those at high risk of developing hypothyroidism. ${ }^{8}$

\section{Management challenges}

Myxoedema coma is a medical emergency and the following principles are essential in its management: (a) intensive care treatment for continuous monitoring of the cardiorespiratory status and for ventilatory support (b) appropriate fluid management and correction of hypotension and abnormal electrolyte levels, (c) aggressive management of precipitating factors and steroid supplementation if required, (d) thyroid hormone replacement. $^{4}$

Our first challenge was managing our patient with $\mathrm{MC}$ with poor prognostic factors such as hypotension, bradycardia, sepsis and a low GCS ${ }^{9,10}$ on the medical ward without adequate cardiopulmonary monitoring and supT4 port due to the limited capacity of our ICU at the time. pmollt Ghana it is not uncommon to find secondary and tertiary healthcare facilities where ICUs are either not available or not readily accessible.

Her altered sensorium was as a result of both the myxoedema coma and severe hyponatraemia; an indication for primary treatment of hyponatremia. ${ }^{11}$ The pathophysiology of hyponatraemia in the setting of MC is multifactorial. $^{12,13,14}$ It is well established that the overly rapid correction of hyponatremia increases the risk of developing Osmotic Demyelination Syndrome (ODS). ${ }^{11,15}$ Serum sodium concentration $<105 \mathrm{mmol} / \mathrm{L}$ and hypokalaemia, both of which our patient had, are some of the factors associated with a high risk of ODS. ${ }^{6}$

Therefore adhering to recommended rate of correction of sodium of 4-8 $\mathrm{mmol} / \mathrm{L}$ in first 24 hours and 12$14 \mathrm{mmol} / \mathrm{L}$ within 48 hours was extremely critical. ${ }^{17}$ The use of hypertonic saline in the management of our patient was life-saving, however the difficulty was the availability of hypertonic saline making its administration erratic. Secondly, the recommended 4 to 6hourly monitoring of electrolytes to ensure the appropriate correction rate of hyponatraemia ${ }^{11}$ was a challenge due to the high cost of biochemical tests.

Indeed all the endocrine-related laboratory investigations and most of the other biochemical tests were performed outside the hospital at a greater cost to our patient because the hospital's laboratory was not running these tests at the time. Furthermore, the timely receipt of results for meaningful interpretation and appropriate intervention was sometimes a major obstacle. We were only able to repeat sodium level after 48 hours of therapy and fortunately the rate of rise of $13 \mathrm{mmol} / \mathrm{L}$ seen in our patient did not exceed the recommended rate.

\section{Thyroid hormone replacement}

Thyroid hormone therapy remains the backbone of treatment of patients with MC. The major considerations of thyroid hormone therapy are the dose and route of administration, which have a bearing on the absorption, distribution, onset of action, efficacy and safety of the administered hormone preparation. ${ }^{4}$

The initial recommended treatment is IV T4 $100-500 \mu \mathrm{g}$ as a bolus to saturate the body pool followed by T4 at a dose of 50-100 $\mu \mathrm{g}$ daily IV or orally. ${ }^{1}$ The T4 concentrations rise acutely to levels above normal and slowly gets converted to T3 the active hormone. ${ }^{18}$ However in the setting of severe illness, there may be a decreased conversion of T4 to T3 favouring the use of T3 by some in the management of $\mathrm{MC}{ }^{19}$ 
On the other hand, it should be noted that thyroid hormone administration is associated with the risk of precipitating angina, heart failure or an arrhythmia and treatment should be started slowly especially among those with underlying cardiovascular disease. ${ }^{1,20}$ Our choice of therapy was limited to only oral T4 due to the lack of both IV preparations. Although oral T4 via NG tube has proved to be equally effective, a major drawback has been the poor absorption of orally administered drugs in $\mathrm{MC}^{4}$

Against the backdrop of a possible myocardial infarction and in the absence of cardiac monitoring coupled with delays in confirming the diagnosis of myocardial infarction in this case, a relatively lower dose of oral T4 was cautiously given via NG tube. Despite the challenges encountered in her management coupled with the presence of significant predictors of mortality at presentation, our patient made a remarkable recovery.

\section{CONCLUSION}

Myxoedema coma is a rare medical emergency which is associated with a high mortality rate. To improve the outcome of patients with myxoedema coma in similar settings and in the absence of local guidelines, early diagnosis and the adoption of the management strategies employed in this case are recommended. Furthermore, there is the need for the formulation of local guidelines for the management of myxoedema coma. Ultimately to overcome these management challenges, the collaborative efforts of health institutions, policy makers and governmental bodies are needed to ensure the availability and accessibility of the necessary resources to guarantee optimum care in Myxoedema coma.

\section{REFERENCES}

1. Wartofsky L. Myxoedema coma. Endocrinol Metabol Clin North America, 2006; 35:687-698.

2. Galofr'e JC, Garc'1a-Mayor RV. Densidad de incidencia del coma mixedematoso. Endocrinologia 1997;44: 103-104.

3. Rodríguez I, Fluiters E, Pérez-Méndez LF, et al. Factors associated with mortality of patients with myxoedema coma: prospective study in 11 cases treated in a single institution. $J$ Endocrinol 2004;180:347-350

4. Mathew V, Misgar RA, Ghosh S, Mukhopadhyay P Myxedema Coma: A New Look into an Old Crisis. J Thyroid Research 2011;1-7

5. Cooper DS, Greenspan FS, Ladenson PW. The thyroid gland. In: Gardner DG, Shoback D, editors.
Greenspan's basic and clinical endocrinology. 8th ed. New York: McGraw-Hill; 2007:209-280

6. Gardner DG. Endocrine emergencies. In: Gardner DG, Shoback D, editors. Greenspan's basic and clinical endocrinology. 8th ed. New York: McGraw-Hill; 2007:868-893

7. Dutta P, Bhansali A, Masoodi S, Bhadada S, et al. Predictors of outcome in myxoedema coma: a study from a tertiary care centre. Critical Care 2008;12; R1.

8. American Thyroid Association and American Academy of Clinical Endocrinologist Guidelines for Hypothyroidism in Adults. Endocr Pract 2012; 18: 998-1028.

9. Hylander B, Rosenquist U. Treatment of myxoedema coma-factors associated with fatal outcome. Acta Endocrinologica 1985;108: 65-71.

10. Yamamoto T, Fukuyama J, Fujiyoshi A. Factors associated with mortality of myxedema coma: report of eight cases and literature survey. Thyroid 1999; 9:1167-1174.

11. Adrogue HJ, Madias NE. The Challenge of Hyponatremia. J Am Soc Nephrol 2012; 23: 1140-1148

12. Kevin M. Pantalone and Betul A. Hatipoglu. Hyponatremia and the Thyroid: Causality or Association? J. Clin. Med. 2015; 4: 32-36

13. Derubertis, F.R., Jr.; Michelis, M.F.; Bloom, M.E.; Mintz, D.H.; Field, J.B.; Davis, B.B. Impaired water excretion in myxedema. Am. J. Med. 1971; 51: 41-53.

14. Skowsky, W.R.; Kikuchi, T.A. The role of vasopressin in the impaired water excretion of myxedema. Am. J. Med. 1978; 64: 613-621

15. Moritz MI, Ayus JL. The pathophysiology and treatment of hyponatremia encephalopathy: an update. Nephrol Dial Transplant 2003; 18: 24862491.

16. Karp BI, Laureno R. Pontine and extrapontine myelinolysis: a neurologic disorder following rapid correction of hyponatremia. Medicine 1993; 72: 359373.

17. Stern RH, Nigweller SU, Hix JK. The treatment of hyponatremia. Semin Nephrol 2009;29:282-299

18. Ridgway EC, McCammon JA, Benotti J, Maloof F. Acute metabolic responses in myxedema to large doses of intravenous L-thyroxine. Ann Int Med 1972; 77:549-555.

19. Wartofsky L, Burman KD. Alterations in thyroid function in patients with systemic illness: the thyroid sick syndrome. Endocr Rev 1982; 3:164-217.

20. Gupta KJ. Myxedema coma: A sleeping giant in clinical practice. Am J Med 2013;126: e3-e4 